\title{
Statistical analysis of AISI304 austenitic stainless steel machining using Ti(C, N)/Al2O3/TiN CVD coated carbide tool
}

\author{
Sofiane Berkani ${ }^{\mathbf{a}^{*}}$, Mohamed Athmane Yallese ${ }^{\mathrm{a}}$, Lakhdar Boulanouar ${ }^{\mathrm{b}}$ and Tarek Mabrouki $^{\mathrm{c}, \mathrm{d}}$
}

${ }^{a}$ Mechanics and Structures Research Laboratory (LMS), May 8th 1945, University of Guelma, Guelma, Algeria

${ }^{b}$ Advanced Technologies in Mechanical Production Research Laboratory (LRTAPM), Mechanical Engineering Department, Badji Mokhtar University of

Annaba, P.O Box 12, Annaba 23000, Algeria

${ }^{c}$ LaMCoS, CNRS, INSA-Lyon UMRS259, Lyon University, Lyon, France

${ }^{d}$ Université de Tunis El-Manar, ENIT, BP-37, Le Belvédère 1002, Tunis, Tunisie

\section{H R O N I C L E}

\section{Article history:}

Received January 162015

Received in Revised Format

April 102015

Accepted April 162015

Available online

April 172015

Keywords:

Machinability

AISI304

Stainless steel

CVD coated carbide tool

ANOVA analysis

Regression models

RSM method

\begin{abstract}
A B S T R A C T
The present research work investigated the machining of AISI304 austenitic stainless steel in terms of machining force evolution, power consumption, specific cutting force and surface roughness where a factorial experiment design and analysis of variance technique were used and several factors were evaluated for their effects on each level. The case of dry turning process was studied based on design of experiments in order to obtain empirical equations characterizing material machinability according to cutting conditions such as cutting speed, feed rate and depth of cut and the latter ones were put in relationship with the machining output variables (Ra, Fc, Kc and Pc) through the response surface methodology (RSM). Results revealed that feed rate was the most preponderant factor affecting surface roughness (71.04\%). However, the depth of cut affects considerably cutting force and cutting power by $(60.74 \%$ and $67.11 \%)$, respectively. In addition, the specific cutting force was found affected significantly by cutting speed with a contribution of $41.43 \%$. The quadratic model of RSM associated with response optimization technique and composite desirability was used to find optimum values of machining parameters (104.54 m/min, $0.08 \mathrm{~mm} / \mathrm{rev}$ and $0.295 \mathrm{~mm})$.
\end{abstract}

\begin{tabular}{|clcl|}
\hline \multicolumn{2}{l}{ Nomenclature } & & \\
$\mathrm{V}_{\mathrm{c}}$ & cutting speed $(\mathrm{m} / \mathrm{min})$ & ASS & austenitic stainless steel \\
$f$ & feed rate $(\mathrm{mm} / \mathrm{rev})$ & ANOVA & analysis of variance \\
$\mathrm{a}_{\mathrm{p}}$ & depth of cut $(\mathrm{mm})$ & $\mathrm{RSM}$ & response surface methodology \\
$\mathrm{R}_{\mathrm{a}}$ & arithmetic mean roughness $(\mu \mathrm{m})$ & $\mathrm{DF}$ & degrees of freedom \\
$\mathrm{Fc}$ & tangential force $(\mathrm{N})$ & $\mathrm{Seq} \mathrm{SS}$ & sequential sum of squares \\
$\mathrm{Kc}$ & specific cutting force $(\mathrm{MPa})$ & Adj $\mathrm{MS}$ & adjusted mean squares \\
$\mathrm{Pc}$ & cutting power $(\mathrm{w})$ & Cont $\%$ & contribution ratio $(\%)$ \\
& & $\mathrm{R}^{2}$ & coefficient of determination $(\%)$ \\
\hline
\end{tabular}

* Corresponding author.

E-mail: berkanis246@yahoo.fr (S. Berkani)

(c) 2015 Growing Science Ltd. All rights reserved.

doi: $10.5267 /$ j.ijiec.2015.4.004 


\section{Introduction}

Stainless Steels are Fe-C alloys with more than $11 \%$ of Cr. Within this family, austenitic alloys are the most resistant to corrosion. Among the austenitic steels, the AISI 304 grade (EN1.4307) is commonly used in industries thanks to its low corrosion and high mechanical properties (ultimate tensile strength is approximately $590 \mathrm{MPa}$ ). This alloy contains $18 \% \mathrm{Cr}$ and $8 \% \mathrm{Ni}$, with maximum carbon composition of $0.08 \%$. Austenitic stainless steels have FCC atomic structure and are considered as non-magnetic alloys. For these reasons, AISI 304 grade is used in large number of specific applications. It is also exploited in chemical equipment, cooking equipment, cryogenic vessels, evaporators, food processing equipment, hospital surgical equipment, kitchen sinks, marine equipment, pressure vessels, valves and shipping drums. This steel presents very severe physico-chemical properties as high temperature strength, low thermal conductivity, high ductility and rapid work-hardening during machining.

In order to improve machinability of AISI 304, many research works have been employed. Indeed, Korkut et al. (2004) have made a parametric study during the machining of AISI 304 austenitic stainless steel. Their aim was to determine optimum cutting speed leading to the lowest tool flank wear. Authors have mentioned that poor performance of the tool at lower cutting speeds can be explained by the influence of the temperature $(t)$ increase in the cutting tool. This is due to the generation of heat during the machining of AISI 304 stainless steel, which is not dissipated rapidly because of the low thermal conductivity of this material.

Akasawa et al. (2003) have underlined that additive elements have a significant influence on the machinability of austenitic stainless steels. During dry and wet turning using K10 carbide tools, pre-cited authors found that dry cutting process produces the rougher surface compared with the wet one. The resulfurization and copper addition were the origin of the decreasing in the cutting force. Also, it can be noticed that resulfurization deteriorates the surface texture in dry cutting, particularly at lower cutting speeds.

Paro et al. (2004) investigated the machining of conventional cast stainless steel with a HIPed (meanshot isostatic pressing) NiTi coating. They concluded that an increased supply of cutting fluid has an advantageous effect on the surface properties. Authors remarked also that the amount of stainless steel adhering to the NiTi walls is decreased when cutting fluid is injected through the spindle. They also underlined that an increase in feed rate will decrease the surface quality.

Paro et al. (2001) studied the tool wear and machinability of stainless steels. It was found that in turning tests of AISI 304 trial materials, wear mechanisms induce catastrophic failure of tool nose due to high cutting forces and sharp edge chipping. The presence of Built-up Edge (BUE) decreases the machinability of AISI 304 trial materials, and the higher the cutting speed, the lower the tool life. Noordin et al. (2007) conducted dry turning of tempered martensitic stainless tool steel using coated cermet and coated carbide tools. They concluded that side cutting edge angle influenced the tool life when it increases from 0 to 5 degrees. They stated that the flank wear and catastrophic failure are the two main types of tool failure modes when machining hardened StavaxESR steel with KT 315 at the various cutting conditions.

Xingzhong et al. (1999) studied the wear behavior of Si3N4 ceramic cutting tool material against stainless steel in dry and water-lubricated conditions. They have remarked that higher load brings about more severe adhesive wear and micro-fracture wear of the ceramic. They concluded that the higher the cutting speed, the higher is the friction generated by heat of the rubbing surfaces. This will accelerate adhesion between the rubbing surfaces, increasing adhesion wear and micro-fracture. Tekiner and Yesilyurt (2004) have made an investigation of the cutting parameters depending on process sound emission during turning of AISI 304 austenitic stainless steel. This study was carried out to determine the optimal cutting parameters according to the cutting process sound, generated during machining. The feed rate and cutting 
speed were determined according to the chip form, surface roughness, flank wear, built-up-edge of the machined samples and machine tool power consumption. They found that optimal cutting parameter are cutting speed of $165 \mathrm{~m} / \mathrm{min}$ and feed rate of $0.25 \mathrm{~mm} / \mathrm{rev}$ give. Their experiment showed that with the change of cutting parameters, cutting sound pressure change also. E.g. if there is a negative event in cutting process, the cutting sound pressure level will suddenly increase or decrease.

El-Tamimi and El-Hossainy (2008) have investigated the evolutions of tool life, cutting force components and surface roughness of AISI 302 stainless steel according cutting parameters. They concluded that the main tool wear mechanism is adhesion wear caused by welding between tool and ship. They noted that feed rate and depth of cut are the most effective factors on the cutting forces. Ciftci (2006) studied the machinability of two austenitic stainless steels. He has carried out turning tests on AISI 304 and AISI 316 austenitic stainless steels using TiC/TiCN/TiN and TiCN/TiC/Al ${ }_{2} \mathrm{O}_{3}$ coated cemented carbides. He concluded that cutting speed affects the machined surface roughness value, significantly. Also, he has remarked that, until a minimum value of $180 \mathrm{~m} / \mathrm{min}$, higher the cutting speed, lower the roughness values. This behavior can be explained by the decrease of built-up edge formation. When cutting speeds are higher than $180 \mathrm{~m} / \mathrm{min}$, this causes an increase in surface roughness attributed to the increasing of cutting tool nose wear. Ciftci (2006) noted that TiC/TiCN/TiN coated cutting tools gave lower cutting forces than TiCN/TiC/Al2O3 coated tools because TiN top coating layer generates lower friction coefficient.

Lin and Shyu (2000) used different coated drills (TiN, TiCN, CrN and TiALN) to investigate tool life and exit Burr using variable feeds when drilling stainless steel. They concluded that TiN and TiCN coated drills were more suitable that the CrN and TiALN coated drills when machining AISI 304 austenitic stainless steel. Selvaraj and Chandramohan (2010) examined surface roughness during machining of AISI 304 ASS in dry turning operation using TiC and TiCN coated tungsten carbide cutting tool. It was noted that feed rate, cutting speed and depth of cut affect surface roughness evolution with a contribution of 51.84\%, 41.99\% and 1.66\%, respectively. Kaladhar et al. (2012) applied Taguchi method to determine the optimum process parameters for turning of AISI 304 using CVD coated cutting tool. The methodology of ANOVA was used to analyze the influence of cutting conditions. It was concluded that cutting speed affected the machined surface roughness significantly (46.05\%) followed by nose radius (23.7\%). The depth of cut has a large significance on material removal rate (61.31\%) followed by cutting speed $(20.40 \%)$.

Kulkarni et al. (2013) have focused their research on dry turning of AISI 304 ASS using AlTiCrN coated insert. The effect of cutting parameters on surface finish, cutting force, tool wear, ship thickness and tool life have been studied. It was found that superior surface finish and minimum cutting force were observed at cutting speed of $320 \mathrm{~m} / \mathrm{min}$ and feed rate of $0.08 \mathrm{~mm} / \mathrm{rev}$ whereas optimum tool wear was found in the range of (200 to 260) $\mathrm{m} / \mathrm{min}$ cutting speed. Wagha et al. (2013) studied the machinability of AISI 304 using coated carbide tools. They observed that when feed rate increases, surface roughness increases where as it decreases with cutting speed. Also, it was underlined that, the higher the cutting speed the higher tool-chip interface temperature. This is due to low thermal conductivity of the coating as well as AISI 304 work material. Further, AlCrN/TiAlN coated cutting tools gave lower cutting forces due to the lower friction coefficient of the coating. Mahdavinejad and Saeedy (2011) tried to investigate the influence of cutting conditions on machining of austenitic stainless steel with cutting fluid and in dry conditions. Authors have noted that cutting speed is the main parameter which affect flank wear and as cutting speed increases to $175 \mathrm{~m} / \mathrm{min}$, the flank wear decreases.

Hasan and Thamizhmanii (2010) analyzed tool wear during turning of AISI 440C martensitic stainless steel using CBN cutting tool. They found that flank and crater wears were caused by severe abrasion phenomenon and also by high generation of heat during machining especially at low cutting speed, and low feed rate. 
In the present contribution, the investigation of machinability of AISI 304 austenitic stainless steel with $\mathrm{Ti}(\mathrm{C}, \mathrm{N}) / \mathrm{Al}_{2} \mathrm{O}_{3} / \mathrm{TiN}$ ” CVD coated carbide inserts is presented. Evolutions of cutting force (Fc), cutting power (Pc), specific cutting force (Kc) and surface roughness (Ra) has been studied according to cutting parameters during a turning operation. To analyze the effects of cutting speed (Vc), feed rate $(f)$ and depth of cut (ap) on the performance of machining, the response surface methodology (RSM) based mathematical models were developed. Quadratic models were developed for deferent cutting cases and the adequacy of such models was tested through the analysis of variance (ANOVA).

\section{Experimental procedure}

\subsection{Response surface methodology (RSM)}

In order to investigate the influence of machining parameters on the evolutions of surface roughness $(\mathrm{Ra})$, cutting force $(\mathrm{Fc})$, specific cutting force $(\mathrm{Kc})$ and cutting power $(\mathrm{Pc})$ only, three machining parameters were considered in the work, which are the cutting speed $\left(V_{c}\right)$, the feed rate $(f)$ and the depth of cut (ap). These machining parameters should be chosen as independent input variables. The desired responses were Ra, Fc, Kc and Pc which are assumed to be affected by the pre-cited cutting parameters. RSM is recognized as a statistical technique based on simple multiple regressions. Using this technique, the effect of two or more factors on quality criteria can be investigated and optimum values could be obtained. The RSM was employed for modeling and analysis of the machining parameters during turning process in order to analyze machinability performances regarding surface roughness and cutting force. In the RSM design adopted, there should be at least three levels for each factor. Therefore the factor values that are not actually tested using fewer experimental combinations and combinations themselves can be estimated. The results are expressed in 3D series or counter map. In the procedure of analysis, the approximation of response (Y) was proposed using the fitted second-order polynomial regression model which is commonly called the quadratic model of Y. The latter can be written in Eq. (1) as follow,

$$
Y=a_{0}+\sum_{i=1}^{3} a_{i} X_{i}+\sum_{i=1}^{3} a_{i i} X_{i}^{2}+\sum_{i<j} a_{i j} X_{i} X_{j}+\varepsilon,
$$

where $a_{0}$ is constant, $a_{i}, a_{i i}$ and $a_{i j}$ represent the coefficients of linear, quadratic and cross product terms, respectively. $X_{i}$ reveals the coded variables that correspond to the studied machining parameters such as cutting speed $\left(V_{c}\right)$, feed rate $(f)$ and depth of cut, and $\varepsilon$ is a random experimental error.

\subsection{Experimental design}

In order to develop the mathematical model based on RSM and to minimize the number of tests, a L16 Taguchi standard orthogonal array is adopted as the experimental design method. In the current study, cutting speed, feed rate and depth of cut are identified as the factors, which affect the responses such as machining force, power, specific cutting force and surface roughness. Four levels are defined for each factor and the ranges of the selected factors were based on the preliminary tests. In the present investigation, factors and their levels are presented in Table 1 . The experimental parameters used and the corresponding responses are given in Table 2. The first column of the Table 2 is assigned to cutting speed (Vc), the second to feed rate $(f)$ and the third one to depth of cut (ap). The measurement results of the surface roughness $(\mathrm{Ra})$ and of the cutting force $(\mathrm{Fc})$ are given in the fourth and fifth columns. The sixth and seventh columns are assigned to specific cutting force $(\mathrm{Kc})$ and power $(\mathrm{Pc})$.

\section{Table 1}

Attribution levels of cutting factors

\begin{tabular}{lcccccc}
\hline $\begin{array}{l}\text { Control } \\
\text { parameters }\end{array}$ & Unit & Symbol & \multicolumn{4}{c}{ Levels } \\
\cline { 4 - 7 } Cutting speed & & Vc & 60 & Level 2 & Level 3 & Level 4 \\
Feed rate & $\mathrm{m} / \mathrm{min}$ & $\mathrm{m} / \mathrm{rev}$ & $\mathrm{f}$ & 0.08 & 0.12 & 120 \\
Depth of cut & $\mathrm{mm}$ & $\mathrm{ap}$ & 0.25 & 0.50 & 0.16 & 0.20 \\
\hline
\end{tabular}


Table 2

Orthogonal array for responses

\begin{tabular}{lccccccc}
\hline \multirow{2}{*}{$\mathrm{N}^{\circ}$ Test } & \multicolumn{3}{c}{ Process parameter settings } & \multicolumn{4}{c}{ Machinability characteristics } \\
\cline { 2 - 9 } & $\mathrm{Vc},(\mathrm{m} / \mathrm{min})$ & $f,(\mathrm{~mm} / \mathrm{rev})$ & $\mathrm{ap},(\mathrm{mm})$ & $\mathrm{Ra},(\mu \mathrm{m})$ & Fc, $(\mathrm{N})$ & $\mathrm{Kc},(\mathrm{MPa})$ & Pc, $(\mathrm{w})$ \\
\hline 1 & 60 & 0.08 & 0.25 & 1.05 & 94.93 & 4746.50 & 94.93 \\
2 & 60 & 0.12 & 0.50 & 1.17 & 208.21 & 3470.17 & 208.21 \\
3 & 60 & 0.16 & 0.75 & 1.50 & 346.12 & 2884.33 & 346.12 \\
4 & 60 & 0.20 & 1.00 & 2.35 & 540.18 & 2700.90 & 540.18 \\
5 & 90 & 0.08 & 0.50 & 0.54 & 132.57 & 3314.25 & 198.86 \\
6 & 90 & 0.12 & 0.25 & 0.66 & 86.01 & 2867.00 & 129.02 \\
7 & 90 & 0.16 & 1.00 & 1.04 & 390.61 & 2441.31 & 585.92 \\
8 & 90 & 0.20 & 0.75 & 1.62 & 381.56 & 2543.73 & 572.34 \\
9 & 120 & 0.08 & 0.75 & 0.60 & 168.13 & 2802.17 & 336.26 \\
10 & 120 & 0.12 & 1.00 & 1.03 & 320.80 & 2673.33 & 641.60 \\
11 & 120 & 0.16 & 0.25 & 1.40 & 99.71 & 2492.75 & 199.42 \\
12 & 120 & 0.20 & 0.50 & 1.80 & 248.19 & 2481.90 & 496.38 \\
13 & 150 & 0.08 & 1.00 & 0.70 & 199.55 & 2494.38 & 498.88 \\
14 & 150 & 0.12 & 0.75 & 0.95 & 213.09 & 2367.67 & 532.73 \\
15 & 150 & 0.16 & 0.50 & 1.99 & 191.24 & 2390.50 & 478.10 \\
16 & 150 & 0.20 & 0.25 & 2.86 & 109.13 & 2182.60 & 272.83 \\
\hline
\end{tabular}

\subsection{Means and materials}

The experiments were carried out on the workpiece AISI 304 stainless steel with chemical composition shown in Table 3. The dimensions are $100 \mathrm{~mm}$ for diameter and $400 \mathrm{~mm}$ for length. The machine used in the current work is the lathe 'TOS TRENCIN; model SN40C'. It is equipped with $6.6 \mathrm{~kW}$ spindle power and a maximum spindle speed of $2000 \mathrm{rpm}$. The cutting insert used is SANDVIK “Ti(C,N)/ $\mathrm{Al}_{2} \mathrm{O}_{3} / \mathrm{TiN}$ ” CVD coated carbide referenced as GC2015 (SNMG 12-04-08-MF). The cutting insert were clamped on a right-hand tool holder with designation PSBNR25x25M12.

Table 3

Chemical composition of AISI 304

\begin{tabular}{cccc}
\hline Composition & (Wt. \%) & Composition & $($ Wt. \%) \\
\hline $\mathrm{C}$ & 0.02 & Mn & 1.44 \\
$\mathrm{Cr}$ & 16.91 & Mo & 0.41 \\
$\mathrm{Ni}$ & 7.69 & Fe & 72.10 \\
$\mathrm{Si}$ & 0.33 & Other components & 1.1 \\
\hline
\end{tabular}

Three different components of forces, commonly called, cutting force $(\mathrm{Fc})$, feed force $\left(\mathrm{F}_{\mathrm{f}}\right)$ and depth force $\left(F_{d}\right)$ were measured through the Kistler piezoelectric dynamometer (model 9121) (Fig.1).

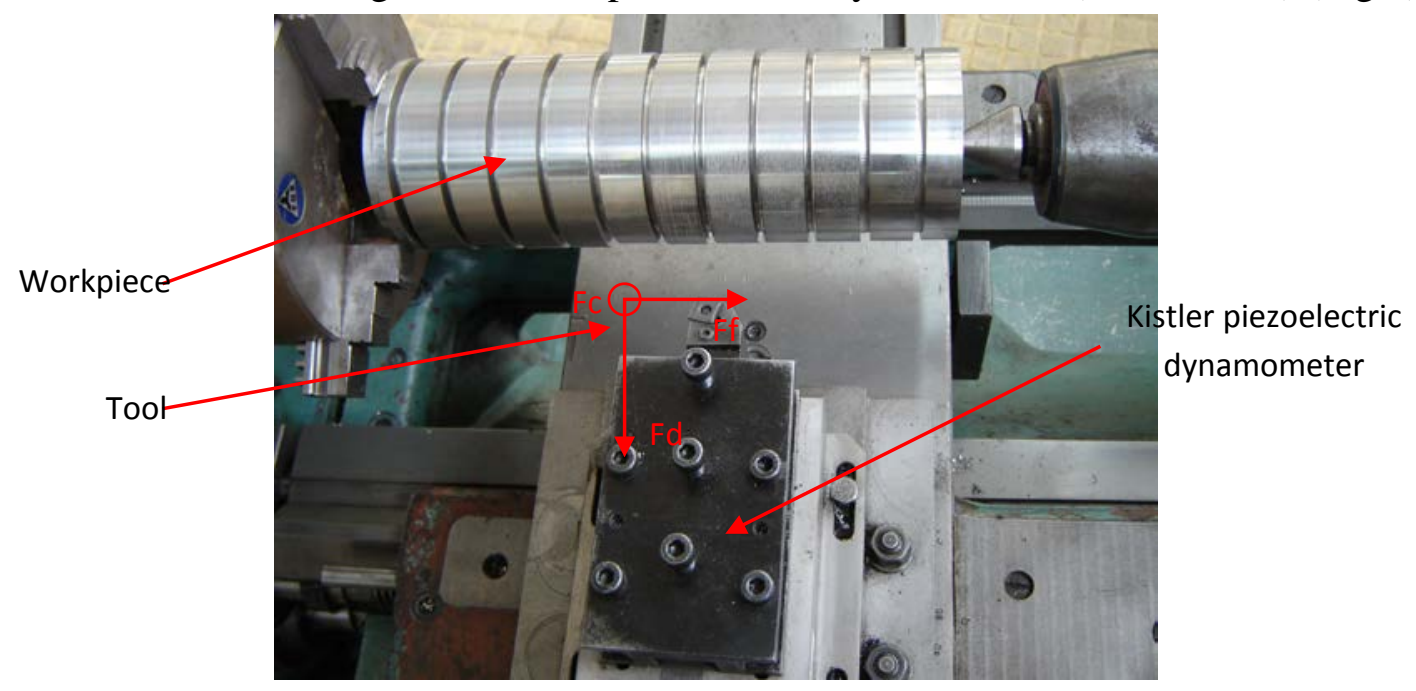

Fig.1. Experimental configuration for measuring cutting force 
The values were monitored continuously and recorded through a three-channel charge amplifier (model 5019) with data acquisition system (Fig. 2). A roughness meter (2d) Surftest 201 Mitutoyo was employed to measure surface roughness Ra, The length examined is $4 \mathrm{~mm}$ with a cut-off of $0.8 \mathrm{~mm}$ and the measured values of $R a$ are within the range $0.05-40 \mu \mathrm{m}$. In order to reduce uncertainties due to resumption operations, roughness values were obtained without disassembling the workpiece.

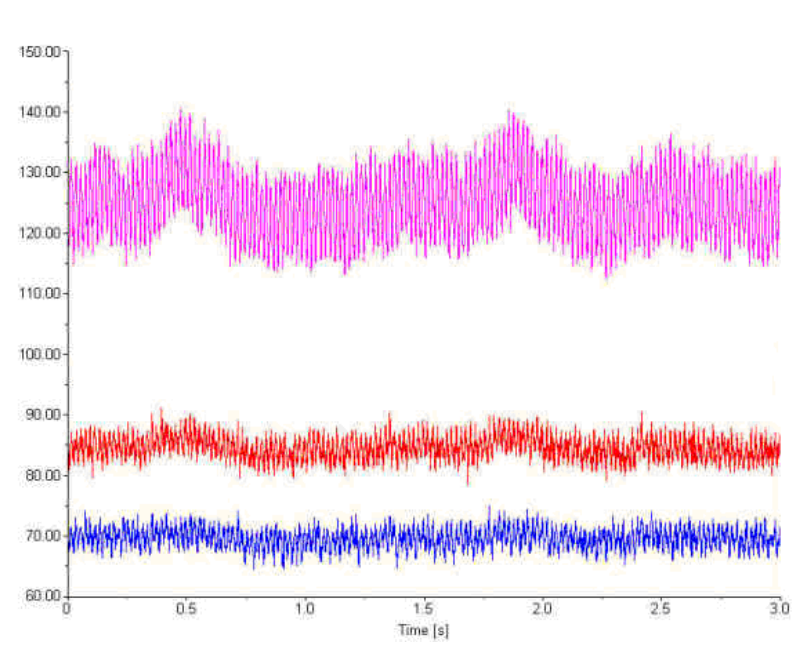

Fig. 2. Sample of acquisition from "Dynoware" software

The other aspects of machinability such as specific cutting force (Kc (N/mm²)) and cutting power (Pc $(\mathrm{N})$ ) are calculated based on the acquisition of Fc, as following:

$$
\begin{aligned}
& K c=\frac{F c}{S}=\frac{F c}{f \times a p} \\
& P c=\frac{F c \times V c}{60}
\end{aligned}
$$

$\mathrm{S}$ is the shear plane area $\left(\mathrm{mm}^{2}\right)$.

\section{Results and discussion}

The effect of cutting conditions on surface roughness, cutting force, specific cutting force and power obtained from the turning of austenitic AISI 304 stainless steel workpiece material is presented in Table 2. In the next discussion is focused on the variance analysis, the regression equation for various responses and the analysis of response surfaces.

\subsection{Analyze of variance}

Tables 4-7 show the results of analysis of variance for surface roughness, tangential force, specific cutting force and cutting power. In addition, the same tables show the degrees of freedom, sum of square, mean of square, F-value and the P-value which is a statistical index used in the analysis of variance. In the statistical significance, the lower P-value means that the tested parameter is more significant. Often the analyzed parameter is considered as significant when the P-value is less than 0.05 . In this study, the significance of all cutting parameters was proved while the P-values of all parameters were less than 0.05. Therefore, it seems to be important to study the effects of each cutting condition on the machining characteristics. The ratio of contribution of different factors and their interactions were also presented. The purpose is to analyze the influence of cutting parameters (Vc, $f$ and ap) on the different cutting responses (Ra, Fc, Kc and Pc). It can be observed from ANOVA results (for Ra presented in Table 4) that the feed rate affects $\mathrm{R} a$ in a significant way. Its contribution is $71.04 \%$ followed by depth of cut with a contribution of $2.17 \%$ and small contribution with $0.97 \%$ for cutting speed. In addition, the term $\left(\mathrm{Vc}^{2}\right)$ has a contribution of about $14.30 \%$. 
Table 4

ANOVA table for Ra

\begin{tabular}{lcccccc}
\hline Source & DF & Seq SS & Adj MS & F-value & P-value & Cont \% \\
\hline Vc & 1 & 0.06384 & 0.55328 & 15.95 & 0.007 & 0.97 \\
$f$ & 1 & 4.67545 & 0.11889 & 3.43 & 0.114 & 71.04 \\
ap & 1 & 0.14281 & 0.01779 & 0.51 & 0.501 & 2.17 \\
Vc $^{2}$ & 1 & 0.9409 & 0.9409 & 27.13 & 0.002 & 14.30 \\
$\mathrm{f}^{2}$ & 1 & 0.19802 & 0.19803 & 5.71 & 0.054 & 3.01 \\
ap $^{2}$ & 1 & 0.0529 & 0.0529 & 1.53 & 0.263 & 0.80 \\
Vc*f & 1 & 0.12149 & 0.12149 & 3.5 & 0.11 & 1.85 \\
Vc*ap & 1 & 0.17529 & 0.17529 & 5.05 & 0.066 & 2.66 \\
$f^{*}$ ap & 1 & 0.00216 & 0.00216 & 0.06 & 0.011 & 0.03 \\
Error & 6 & 0.2081 & 0.03468 & & & 3.16 \\
\hline Total & 15 & 6.58098 & & & & 100 \\
\hline
\end{tabular}

Nevertheless, the influence of cutting conditions on cutting force evolutions shows that the cutting speed has a small effect compared with that of the feed rate and the depth of cut and this can be noted in ANOVA analysis presented in Table 5. The depth of cut has a contribution ratio of $60 \%$ and $25 \%$ for the feed rate, but the cutting speed presents only a $12 \%$.

Table 5

ANOVA table for Fc

\begin{tabular}{ccccccc}
\hline Source & DF & Seq SS & Adj MS & F-value & P-value & Cont \% \\
\hline Vc & 1 & 31332 & 444 & 188.40 & $<0.001$ & 12.34 \\
$f$ & 1 & 63349 & 1 & 380.93 & $<0.001$ & 24.95 \\
ap & 1 & 154244 & 355 & 927.50 & $<0.001$ & 60.74 \\
\hline Vc $^{2}$ & 1 & 350 & 350 & 2.11 & 0.197 & 0.14 \\
$\mathrm{f}^{2}$ & 1 & 21 & 21 & 0.13 & 0.733 & 0.01 \\
ap $^{2}$ & 1 & 145 & 145 & 0.87 & 0.386 & 0.06 \\
Vc*f & 1 & 1 & 1 & 0.00 & 0.951 & 0.00 \\
Vc*ap & 1 & 34 & 34 & 0.20 & 0.668 & 0.01 \\
$f^{*}$ ap & 1 & 3479 & 3479 & 20.92 & 0.004 & 1.37 \\
Error & 6 & 998 & 166 & & & 0.39 \\
\hline Total & 15 & 253953 & & & & 100.00 \\
\hline
\end{tabular}

\section{Table 6}

ANOVA table for Kc

\begin{tabular}{|c|c|c|c|c|c|c|}
\hline Source & $\mathrm{DF}$ & Seq SS & Adj MS & F-value & P-value & Cont \% \\
\hline Vc & 1 & 2386169 & 722643 & 81.83 & $<0.001$ & 41.43 \\
\hline$f$ & 1 & 1657079 & 612362 & 56.83 & $<0.001$ & 28.77 \\
\hline ap & 1 & 611748 & 224022 & 20.98 & 0.04 & 10.62 \\
\hline $\mathrm{Vc}^{2}$ & 1 & 164146 & 164146 & 5.63 & 0.055 & 2.85 \\
\hline $\mathrm{f}^{2}$ & 1 & 176266 & 176266 & 6.04 & 0.049 & 3.06 \\
\hline $\mathrm{ap}^{2}$ & 1 & 7398 & 7398 & 0.25 & 0.632 & 0.13 \\
\hline $\mathrm{Vc}^{*} f$ & 1 & 294009 & 294009 & 10.08 & 0.019 & 5.11 \\
\hline Vc*ap & 1 & 184023 & 184023 & 6.31 & 0.046 & 3.20 \\
\hline$f^{*}$ ap & 1 & 103045 & 103045 & 3.53 & 0.109 & 1.79 \\
\hline Error & 6 & 174958 & 29160 & & & 3.04 \\
\hline Total & 15 & 5758842 & & & & 100.00 \\
\hline
\end{tabular}

The ANOVA results of the specific cutting force and the cutting power are presented in the Tables 6 and 7 , respectively. It can be noted that the depth of cut is the most preponderant parameter which affect the 
power with the contribution of about $67 \%$. The second factor influencing $P c$ is the feed rate with a contribution of about $14 \%$. Although, the cutting speed, its effect is less important and its contribution is 9.91\%. It is clear from the results of ANOVA shown in Table 6 that the cutting speed affect significantly specific cutting force and its contribution is $41.43 \%$. The second parameter influencing specific cutting force is feed rate and its contribution is $28.77 \%$. Hence; the influence of depth of cut is less important and its contribution is just $10.62 \%$.

Table 7

ANOVA table for Pc

\begin{tabular}{ccccccc}
\hline Source & DF & Seq SS & Adj MS & F-value & P-value & Cont \% \\
\hline Vc & 1 & 48353 & 342 & 114.66 & $<0.001$ & 9.91 \\
$f$ & 1 & 69409 & 515 & 164.59 & $<0.001$ & 14.23 \\
ap & 1 & 327301 & 613 & 776.11 & $<0.001$ & 67.11 \\
Vc & 1 & 2205 & 2205 & 5.23 & 0.062 & 0.45 \\
$\mathrm{f}^{2}$ & 1 & 763 & 763 & 1.81 & 0.227 & 0.16 \\
$\mathrm{ap}^{2}$ & 1 & 2658 & 2658 & 6.30 & 0.046 & 0.55 \\
Vc*f $^{*}$ & 1 & 7863 & 7863 & 18.65 & 0.005 & 1.61 \\
Vcap & 1 & 14751 & 14751 & 34.98 & 0.001 & 3.02 \\
$f^{*}$ ap & 1 & 11852 & 11852 & 28.10 & 0.002 & 2.43 \\
Error & 6 & 2530 & 422 & & & \\
\hline Total & 15 & 487685 & & & & 0.52 \\
\hline
\end{tabular}

\subsection{Regression equation for the various responses}

The functional relationship between the dependent variables (Ra, Fc, Kc and Pc) and the investigated independent variables ( Vc, f and ap) were expressed with correlation coefficient $\mathrm{R}^{2}$ corresponding to the regression accuracy. The different quadratic models obtained from statistical analysis can be used to predict the surface roughness, cutting force, specific cutting force and cutting power according to the studied factors. The comparison between experimental and predicted values is presented in (Fig. 3, Fig. 4, Fig. 5 and Fig. 6). The obtained models presenting the evolution of surface roughness, cutting force, specific cutting force and cutting power regarding (Vc, f, and ap) are presented by Eqs. (4-7), respectively).

The Anderson-Darling test and normal probability plots of predicted responses for the surface roughness, cutting force, specific cutting force and machining power are plotted respectively in (Figs. (7-10)). The data follows the straight line, closely. The null hypothesis is that the data distribution law is normal and the alternative hypothesis corresponds to non-normal distribution. Using the P-value which is greater than alpha of 0.05 (level of significance), the null hypothesis cannot be rejected (i.e., the data follow a normal distribution). This implies that the models proposed are adequate.

$$
\begin{aligned}
& R a=4.13-0.06 V c-19.86 f-1.13 a p+0.0003 V c^{2}+69.53 f^{2}+0.92 a p^{2}+0.1 V c . f-0.01 V c . a p-1.56 f . a p \\
& \mathrm{R}^{2}=96.84 \\
& F c=101-1.62 V c-57.19 f+159 a p+0.01 V c^{2}+720 f^{2}+48.19 a p^{2}-0.23 V c . f-0.26 V c . a p+1988 f . a p \\
& \mathrm{R}^{2}=99.61 \\
& K c=11076-65.3 V c-45067 f-4011 a p+0.1 V c^{2}+65600 f^{2}+344 a p^{2}+152 V c . f+19 V c . a p+10821 f . a p \\
& \mathrm{R}^{2}=96.96 \\
& P c=149-1.42 V c-1307 f-209 a p-0.01 V c^{2}-4314 f^{2}-206 a p^{2}+24.9 V c . f+5.46 V c . a p+3669 f . a p \\
& \mathrm{R}^{2}=99.48
\end{aligned}
$$




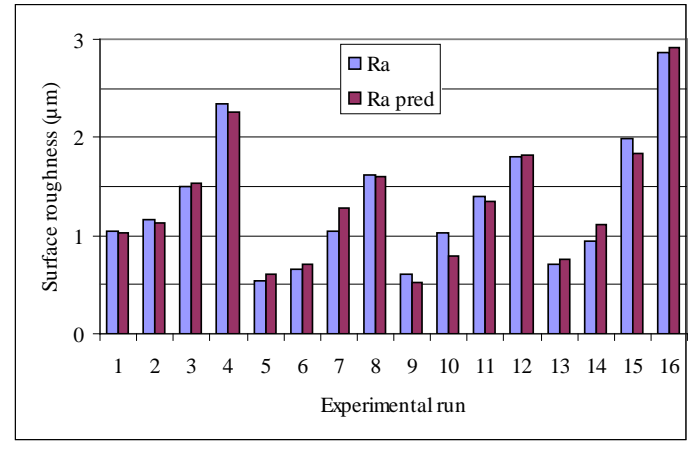

Fig. 3. Experimental and predicted RSM values

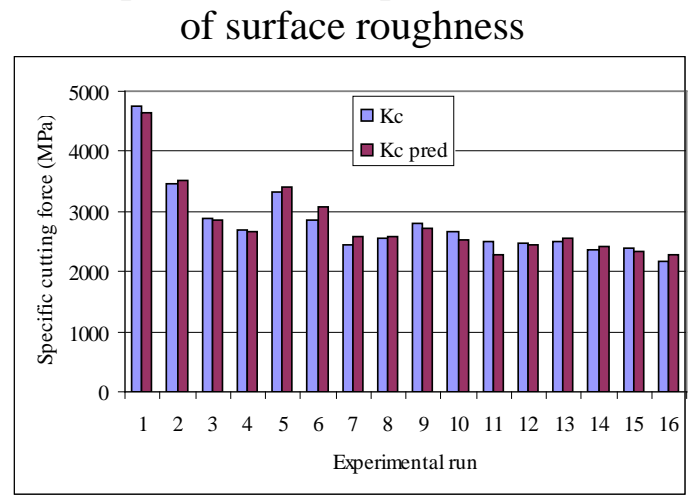

Fig. 5. Experimental and predicted RSM values

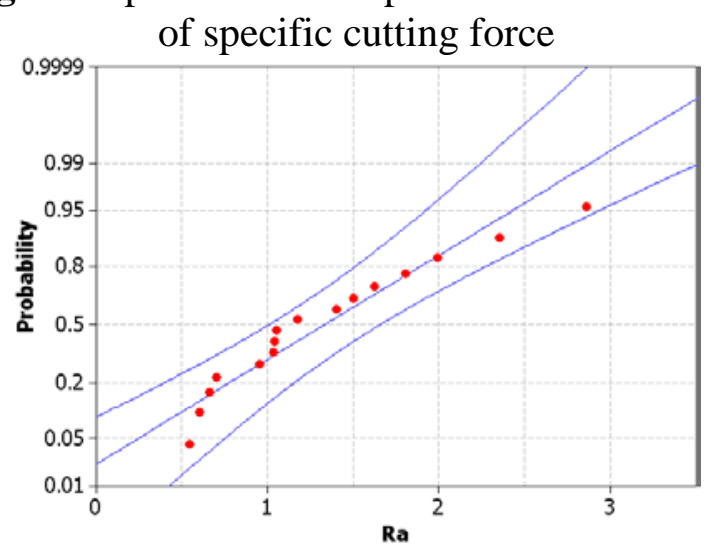

Fig. 7. Normal probability plot for Ra

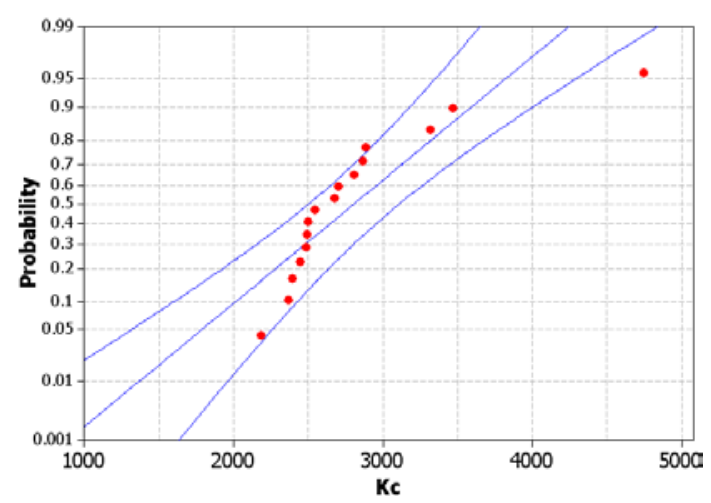

Fig. 9. Normal probability plot for Kc

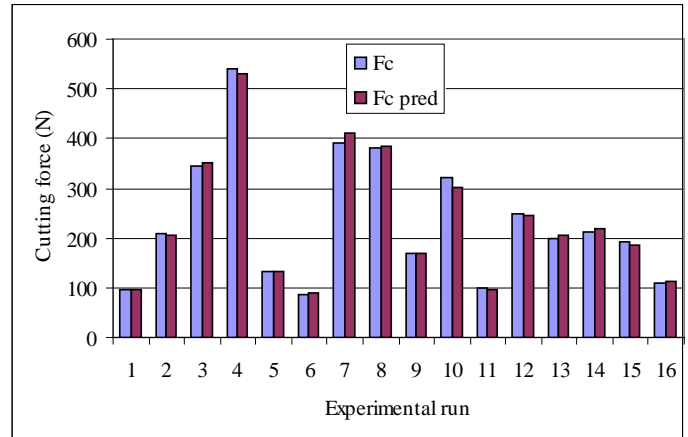

Fig. 4. Experimental and predicted RSM values of cutting force

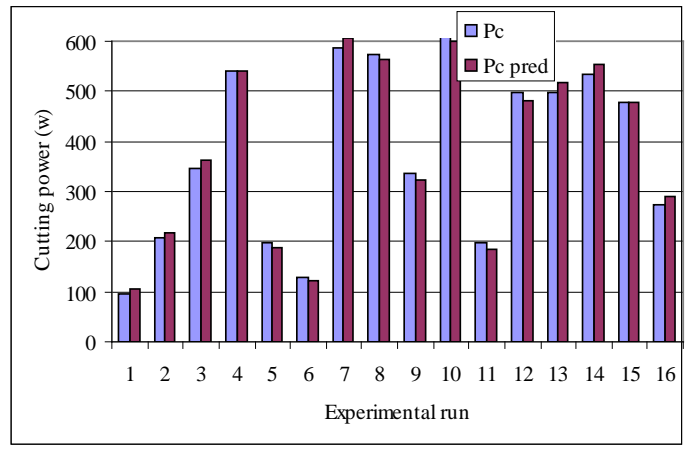

Fig. 6. Experimental and predicted RSM values of cutting power

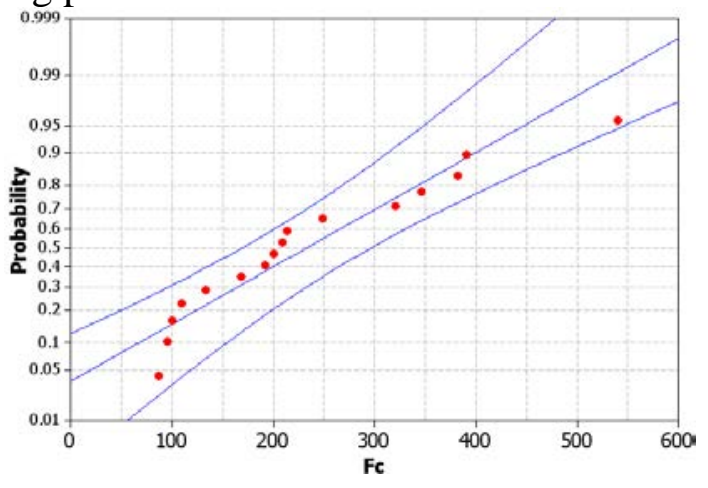

Fig. 8. Normal probability plot for Fc

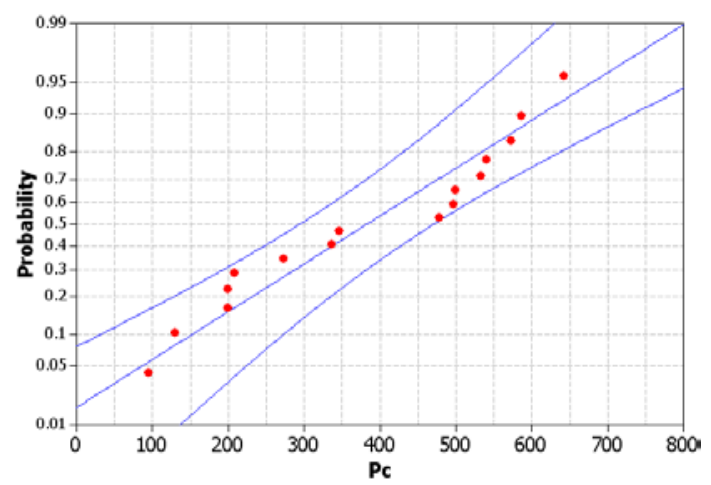

Fig. 10. Normal probability plot for Pc 


\subsection{Responses surface analysis}

\section{a. Surface roughness}

The evolution of the estimated roughness response surface in relationship with cutting parameters (Vc, $f$ and ap) is presented in Fig. 11. It can be shown that the cutting speed has a significant influence on the machined surface roughness. High values of surface roughness are noted in lower values of cutting speed. This can be explained by the presence of built up edge (BUE) (Fig. 12.) on the surface due to the high ductility of austenitic stainless steel. With the increasing of cutting speed, the surface roughness values decrease until a minimum value reached beyond which they increase. The decrease in surface roughness when increasing cutting speed to $100 \mathrm{~m} / \mathrm{min}$ can be explained by the presence of micro-welds on machined surface due to high level heat at cutting zone. At a given height, the built-up edge can be broken and carried away on the machined surface as seen in (Fig.12). Further, increasing the cutting speed causes an increase in surface roughness. This is due to the tool nose wear increase causing the poor surface finish Ciftci (2005).
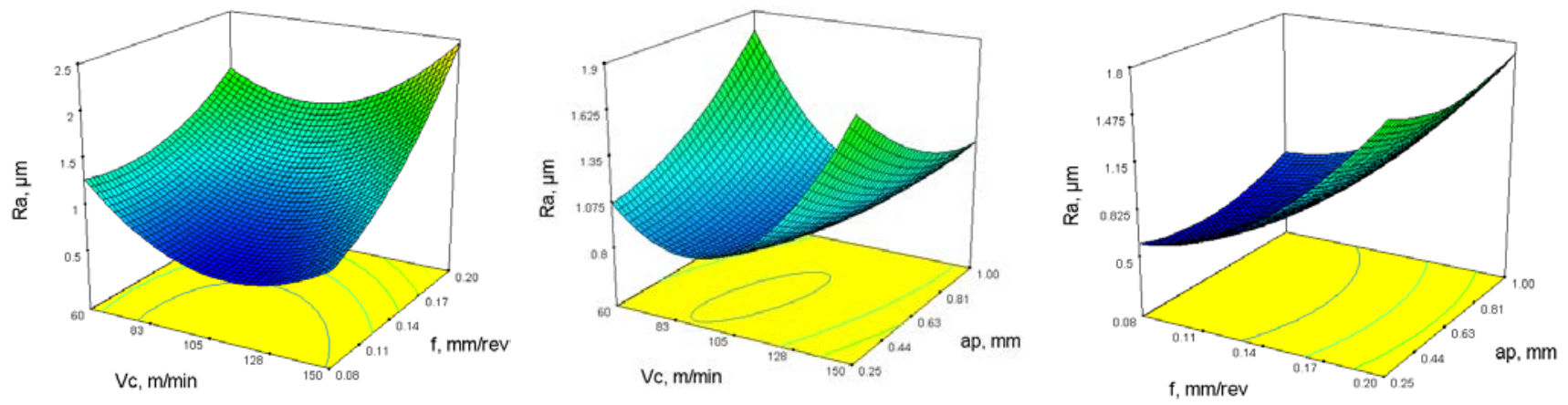

Fig. 11. Surface and contour plots for Ra

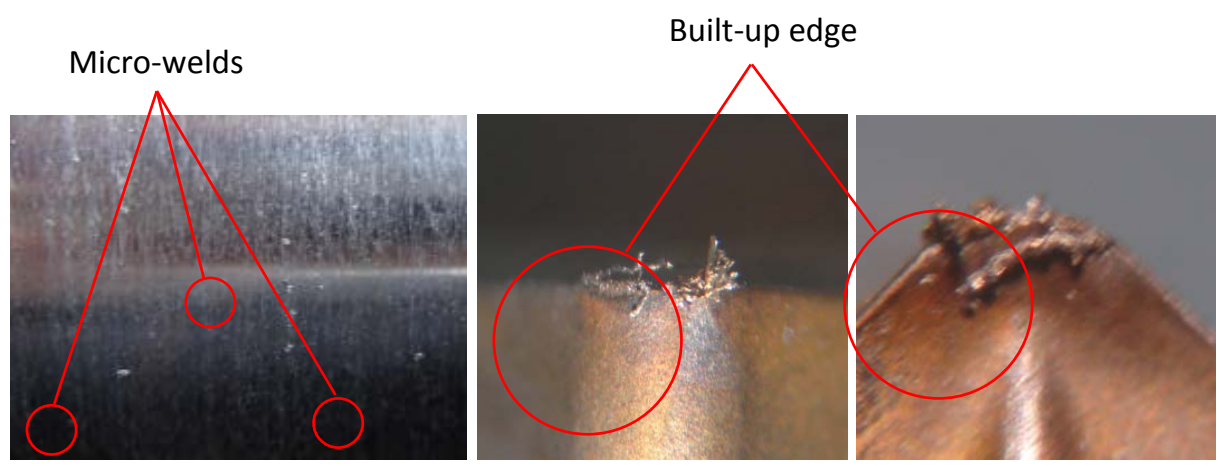

Fig. 12. Micro-weld on machined surface and Built-up edge on cutting insert

\section{b. Tangential cutting force}

The 3D surface plot displayed in Fig. 13 illustrates the effect of cutting parameters on cutting force, Fc. The variation of Fc as a function of the cutting conditions is linear and found to be increased with feed rate and of depth of cut. This behavior is due to the increase of chip section. According to the surface plot, it can be observed that the feed rate has a smaller influence on Fc compared with depth of cut and that's confirmed in ANOVA, previously. Furthermore, the cutting speed affects slightly the tangential force, with increasing of (Vc) the cutting force Fc decrease. This is explained by the increasing of the cutting temperature in the cutting area which leads to the softening of the machined material. This allows removing the material at lower cutting force. Similar observation has been reported by El-Tamimi et al. 
(2010) and Swapnagandha et al. (2013), recording a high forces at lower cutting speed because the chip remains, for long time, in contact with the tool rake face yielding to an increase in the tool-chip contact length. This implies an increase in the friction between the tool and chip that resulted in higher forces.
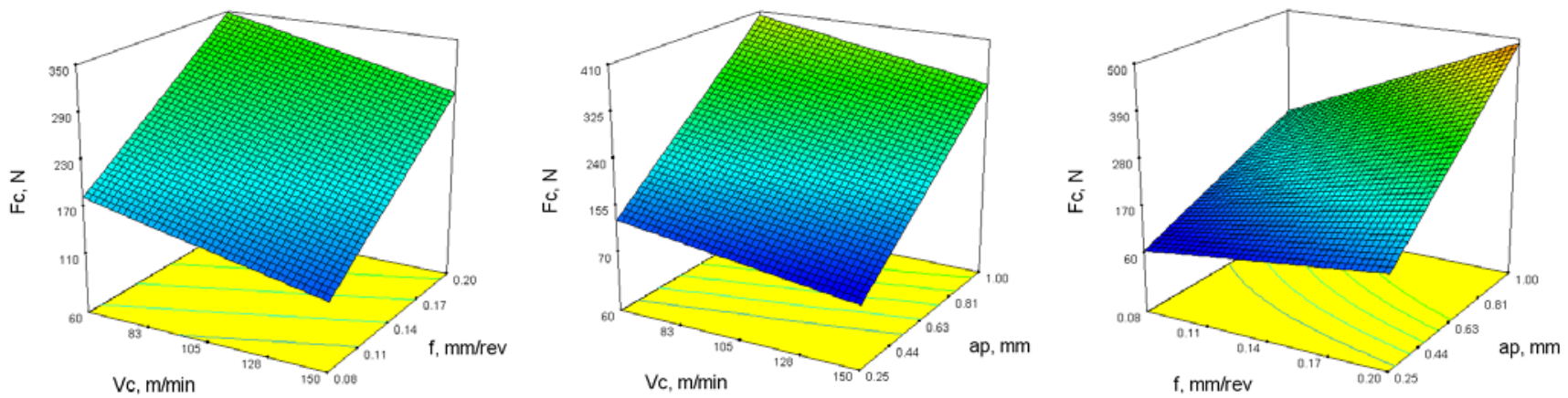

Fig. 13. Surface and contour plots for Fc

\section{c. Power and specific cutting force}

The variation of power with different cutting parameters presented in Fig. 15 shows that power increases with different cutting parameters. It was clear from surface plot that the depth of cut (ap) is the most preponderant parameter affecting the cutting power. When the depth of cut (ap) increases, the tangential force increases. The influence of studied cutting parameters (Vc, $f$, ap) on specific cutting force is illustrated in Fig. 14. It can be remarked that the cutting speed affects considerably Kc when the feed rate increases (up to $0.15 \mathrm{~mm} / \mathrm{rev}$ ), the Kc decreases. Thereafter the specific cutting force exhibits an increasing trend. It is clear from analysis that higher cutting speed with lower feed rate is beneficial to reduce the cutting force and consequently decreasing the specific cutting force.
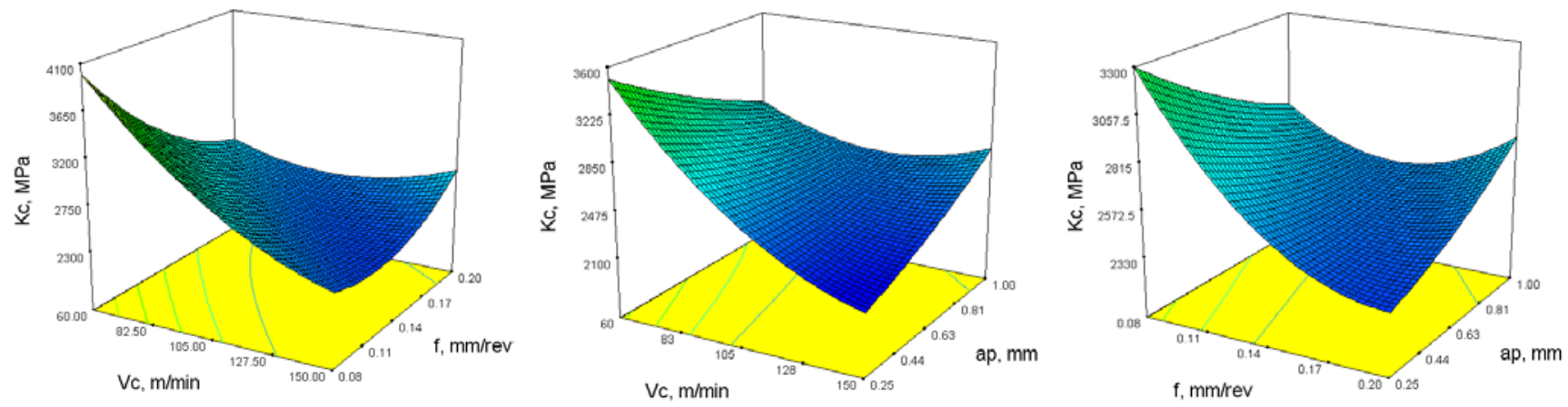

Fig. 14. Surface and contour plots for Kc
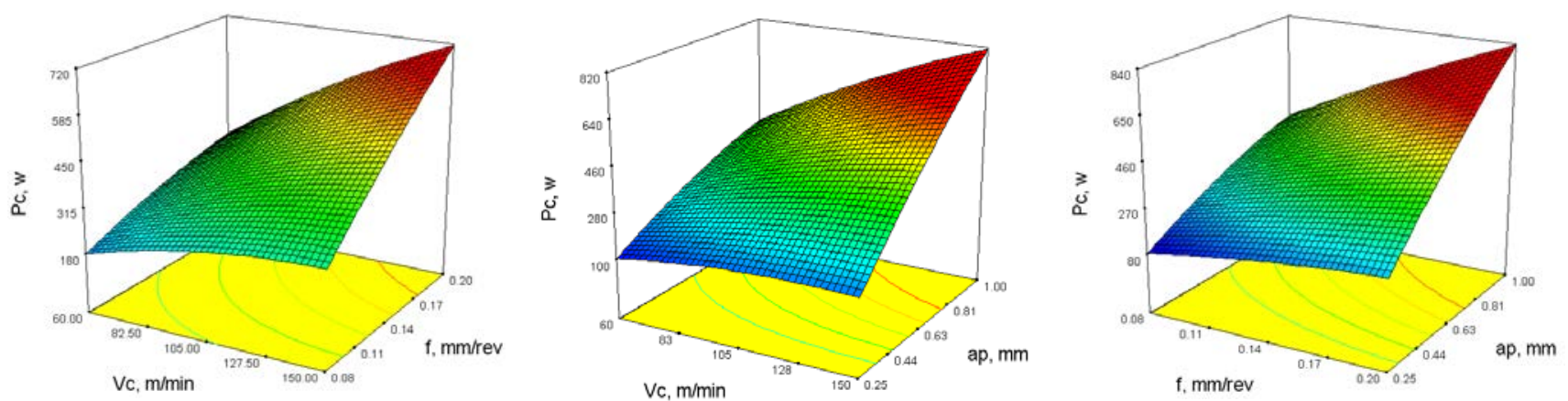

Fig. 15. Surface and contour plots for Pc 


\section{Multiple responses optimization}

One of the most important aims of experimental manufacturing is to identify the desired response values of the optimal cutting parameters. To reach this end, the response surface optimization is an ideal technique for determination of the cutting parameters combination in turning. In the current study, the goal is to minimize the deferent cutting outputs (surface roughness, cutting force, specific cutting force and cutting power). RSM optimization results for cutting phenomenon were shown in Fig. 16. Optimum cutting parameters obtained in Table 8 were found to be cutting speed of $104.5 \mathrm{~m} / \mathrm{min}$, feed rate of 0.08 $\mathrm{mm} / \mathrm{rev}$ and depth of cut of $0.295 \mathrm{~mm}$. The optimized values of (Ra, Fc, Kc and Pc) are (0.57 $\mu \mathrm{m}, 69.35$ N, 3267.20.93 MPa and 95.13w), respectively.

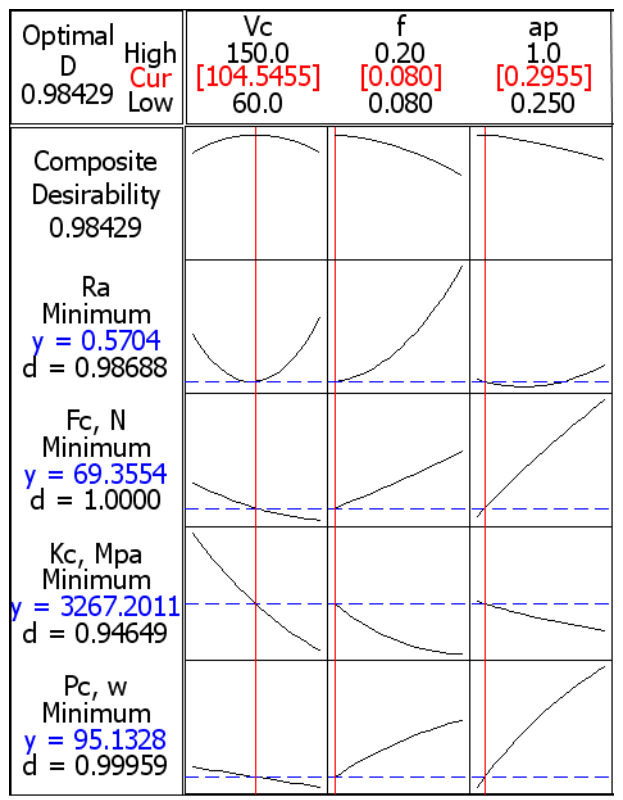

Fig. 16. Response optimization plots for (Ra, Fc, Kc and Pc)

Table 8

Response optimization for

\begin{tabular}{|c|c|c|c|c|c|c|c|c|}
\hline \multirow[b]{2}{*}{ parameters } & \multirow[b]{2}{*}{ Goal } & \multicolumn{3}{|c|}{ Optimum condition } & \multirow[b]{2}{*}{ Lower } & \multicolumn{3}{|c|}{ Predected } \\
\hline & & $\overline{\mathrm{Vc}, \mathrm{m} / \mathrm{min}}$ & $f, \mathrm{~mm} / \mathrm{rev}$ & ap, mm & & Upper & response & Deserability \\
\hline $\mathrm{Ra}, \mu \mathrm{m}$ & Minimum & & & & 0.54 & 2.86 & 0.57 & 0.98 \\
\hline Fc, N & Minimum & 10454 & Q & 0705 & 86.01 & 540.18 & 69.36 & 1.00 \\
\hline $\mathrm{Kc}, \mathrm{MPa}$ & Minimum & 104.54 & 0.08 & 0.295 & 2182.60 & 4746.50 & 3267.20 & $0 . c$ \\
\hline Pc, w & Minimum & & & & 94.93 & 585.92 & 95.13 & 0.99 \\
\hline
\end{tabular}

\section{Confirmation tests}

The confirmation tests were performed for surface e roughness and cutting force in order to verify the adequacy of obtained mathematical models which are Eqs. (4-5). The cutting parameters used in the turning confirmation tests were presented in Table 9.

\section{Table 9}

Cutting conditions used in turning confirmation tests

\begin{tabular}{llll}
\hline Test $\mathrm{N}^{\circ}$ & Vc $(\mathrm{m} / \mathrm{min})$ & $f(\mathrm{~mm} / \mathrm{rev})$ & ap $(\mathrm{mm})$ \\
\hline T1 & 70 & 0.08 & 0.40 \\
$\mathrm{~T} 2$ & 70 & 0.11 & 0.60 \\
$\mathrm{~T} 3$ & 70 & 0.18 & 0.40 \\
$\mathrm{~T} 4$ & 138 & 0.09 & 0.85 \\
$\mathrm{~T} 5$ & 68 & 0.14 & 0.55 \\
\hline
\end{tabular}


The Table 10 shows $t$ as a comparison between the predicted values from the model developed in the present work Eq. (4) and Eq. (5), with the experimental data. From the analysis of Table 10, it can be noted that the calculator error for surface roughness Ra has a maximum value of $8.57 \%$ and a minimum one of $5.81 \%$. For the cutting force Fc the maximum magnitude is about $11.02 \%$ and the minimum one is about $0.16 \%$. As a conclusion, it can be considered that Eqs. (4-5) correlate the evolution of both surface roughness and cutting force with cutting parameters according a reasonable degree of approximation.

Table 10

Confirmation tests for surface roughness and cutting force

\begin{tabular}{|c|c|c|c|c|c|c|}
\hline \multirow{2}{*}{ Test $\mathrm{N}^{\circ}$} & \multicolumn{3}{|c|}{ Surface roughness } & \multicolumn{3}{|c|}{ Cutting force } \\
\hline & Actual & Predicted & Error (\%) & Actual & Predicted & Error (\%) \\
\hline $\mathrm{T} 1$ & 1.30 & 1.22859 & 5.81 & 108.56 & 122.008 & 11.02 \\
\hline $\mathrm{T} 2$ & 1.45 & 1.33551 & 8.57 & 209.46 & 209.117 & 0.16 \\
\hline T3 & 2.14 & 2.29837 & 6.89 & 201.83 & 217.965 & 7.40 \\
\hline $\mathrm{T} 4$ & 1.80 & 1.96319 & 8.31 & 211.55 & 195.976 & 7.95 \\
\hline T5 & 1.57 & 1.66979 & 5.98 & 241.49 & 233.709 & 3.33 \\
\hline
\end{tabular}

\section{Conclusion}

Based on the experimental results and parametric analysis concerning the machining of AISI304 austenitic stainless steel, the following points can be concluded.

1. Cutting speed has a significant influence on the evolution of the machined surface roughness. For small values, it can be noted that cutting speed implies a bad surface finish. This can be explained by the presence of built-up edge and the high ductility of austenitic stainless steels.

2. The feed rate is the most significant factor affecting the surface roughness with $71.04 \%$ contribution in the model total variability followed by depth of cut with $2.17 \%$ and contribution of $0.97 \%$ for cutting speed.

3. Cutting force is highly affected by depth of cut. Its contribution was $60.74 \%$, followed by feed rate with contribution of $24.95 \%$. Cutting speed has a small contribution with $12.34 \%$. Cutting force initially increases with the increase of both depth of cut and feed rate. Also, the lower the cutting force, the lower the cutting speed. This reduction is probably caused by increase in the temperature at the cutting zone which leads to the workpiece softening.

4. Cutting speed has the highest influence on specific cutting force with a contribution of $41.43 \%$ followed by feed rate (28.77\%) and the contribution of $10.62 \%$ for depth of cut. At higher cutting speed and lower feed rate, cutting force is smaller. The latter decreases the specific cutting force.

5. The analysis shows that the depth of cut has a significant effect on the power consumption with a contribution of $67.11 \%$ followed by feed rate (14.23\%) and cutting speed (9.91\%). When studied cutting parameters (Vc, $f$ and ap) increase the cutting power increases.

6. The response optimization shows that the optimal combination of machining parameters are (cutting speed of $104.54 \mathrm{~m} / \mathrm{min}$, feed rate of $0.080 \mathrm{~mm} / \mathrm{rev}$ and depth of cut of $0.295 \mathrm{~mm}$ ) with estimated values of $(0.57 \mu \mathrm{m}$ for Ra, $69.36 \mathrm{~N}$ for Fc, 3267.20MPa for Kc and 95.13 watt for Pc).

7. The confirmation tests indicate that the error related to surface roughness Ra has a maximum value of $8.57 \%$ and a minimum one of 5.81\%) and for the cutting force Fc has a maximum value of $11.02 \%$ and a minimum one $0.16 \%$ ).

\section{Acknowledgements}

This work was achieved in the laboratory LMS (Guelma University, Algeria) and in collaboration with LaMCos (CNRS, INSA-Lyon, France) and Université de Tunis El-Manar, ENIT, BP-37, Le Belvédère 1002, Tunis, Tunisie. The authors would like to thank the Algerian Ministry of Higher Education and 
Scientific Research (MESRS) and the Delegated Ministry for Scientific Research (MDRS) for granting financial support for CNEPRU Research Project, CODE: J0301520140021 (Guelma University).

\section{References}

Akasawa, T., Sakurai, H., Nakamura, M., Tanaka, T., \& Takano, K. (2003). Effects of free-cutting additives on the machinability of austenitic stainless steels. Journal of Materials Processing Technology, 143, 66-71.

Ciftci, I. (2006). Machining of austenitic stainless steels using CVD multi-layer coated cemented carbide tools. Tribology International, 39(6), 565-569.

El-Tamimi, A. M., \& El-Hossainy, T. M. (2008). Investigating the tool life, cutting force components, and surface roughness of AISI 302 stainless steel material under oblique machining. Materials and Manufacturing Processes, 23(4), 427-438.

Gaitonde, V. N., Karnik, S. R., Faustino, M., \& Davim, J. P. (2010). Machinability analysis in turning tungsten-copper composite for application in EDM electrodes. International Journal of Refractory Metals and Hard Materials,28(2), 221-227.

Hasan, S., \& Thamizhmanii, S. (2010). Tool flank wear analyses on AISI 440 C martensitic stainless steel by turning. International Journal of Material Forming,3(1), 427-430.

Kaladhar, M., Subbaiah, K., \& Rao, C. (2012). Parametric optimization during machining of AISI 304 Austenitic Stainless Steel using CVD coated DURATOMIC cutting insert. International Journal of Industrial Engineering Computations, 3(4), 577-586.

Korkut, I., Kasap, M., Ciftci, I., \& Seker, U. (2004). Determination of optimum cutting parameters during machining of AISI 304 austenitic stainless steel.Materials \& Design, 25(4), 303-305.

Kulkarni, A. P., Joshi, G. G., \& Sargade, V. G. (2013). Dry turning of AISI 304 austenitic stainless steel using AlTiCrN coated insert produced by HPPMS technique. Procedia Engineering, 64, 737-746.

Lin, T. R., \& Shyu, R. F. (2000). Improvement of tool life and exit burr using variable feeds when drilling stainless steel with coated drills. The International Journal of Advanced Manufacturing Technology, 16(5), 308-313.

Mahdavinejad, R. A., \& Saeedy, S. (2011). Investigation of the influential parameters of machining of AISI 304 stainless steel. Sadhana, 36(6), 963-970.

Noordin, M. Y., Venkatesh, V. C., \& Sharif, S. (2007). Dry turning of tempered martensitic stainless tool steel using coated cermet and coated carbide tools. Journal of Materials Processing Technology, 185(1), 83-90.

Paro, J. A., Gustafsson, T. E., \& Koskinen, J. (2004). Drilling of conventional cast stainless steel with HIPed NiTi coating. Journal of materials processing technology, 153, 622-629.

Paro, J., Hänninen, H., \& Kauppinen, V. (2001). Tool wear and machinability of X5 CrMnN 1818 stainless steels. Journal of Materials Processing Technology,119(1), 14-20.

Selvaraj, D. P., \& Chandramohan, P. (2010). Optimization of surface roughness of AISI 304 austenitic stainless steel in dry turning operation using Taguchi design method. Journal of Engineering Science and Technology, 5(3), 293-301.

Tekıner, Z., \& Yeşılyurt, S. (2004). Investigation of the cutting parameters depending on process sound during turning of AISI 304 austenitic stainless steel. Materials \& Design, 25(6), 507-513.

Thamizhmanii, S., \& Hasan, S. (2009). Effect of tool wear and forces by turning process on hard AISI 440 C and SCM 440 materials. International Journal of Material Forming, 2(1), 531-534.

Wagh, S. S., Kulkarni, A. P., \& Sargade, V. G. (2013). Machinability studies of austenitic stainless steel (AISI 304) using PVD Cathodic Arc Evaporation (CAE) system deposited AlCrN/TiAlN coated carbide inserts. Procedia Engineering, 64, 907-914.

Xingzhong, Z., Jiajun, L., Baoliang, Z., Hezhou, M., \& Zhenbi, L. (1999). Wear behavior of Si 3 N 4 ceramic cutting tool material against stainless steel in dry and water-lubricated conditions. Ceramics international, 25(4), 309-315. 